\title{
Reliability of the Spanish version of a brief questionnaire on patient satisfaction with gastrointestinal endoscopy
}

\author{
A. Sánchez del Río, O. Alarcón Fernández, J. S. Baudet, Z. Sainz Menéndez, M. Socas Méndez \\ and G. Piera Jaén
}

Unit of Digestive Diseases. Hospiten Group of Hospitals. Santa Cruz de Tenerife. Spain

\begin{abstract}
Background: there has not been a validated questionnaire available in Spanish to evaluate patient satisfaction with gastrointestinal endoscopy. Our aim was to evaluate the external validity and internal consistency of the Spanish version of a questionnaire on patient satisfaction with gastrointestinal endoscopy elaborated by the American Society for Gastrointestinal Endoscopy.

Design: prospective questionnaire validation study.

Patients and methods: a total of 485 consecutive patients referred to two different hospitals for endoscopy were interviewed by telephone. Internal consistency was studied using Cronbach's alfa test and corrected item-total correlations (CITC). External validity was determined using a mailed questionnaire completed by 185 patients -correlations between telephone and postal responses were calculated, as well as the correlation with the total score obtained.

Results: Cronbach's alfa was 0.82 and mean CITC was 0.59 . Weighted kappa values for the same questionnaire items performed by telephone or mail varied between 0.51 and 0.81 . Total score correlation was 0.78 . Internal consistency and external validity were not affected by differences in the administration of the questionnaire (mail or by telephone), different interviewers, type of endoscopy, or source of patients.

Conclusions: the Spanish version of the ASGE questionnaire on satisfaction with endoscopy is valid, reliable, and reproducible.
\end{abstract}

Key words: Gastrointestinal endoscopy. Patient satisfaction. Health care evaluation mechanisms. Questionnaires. Validation studies.

Sánchez del Río A, Alarcón Fernández O, Baudet JS, Sainz Menéndez Z, Socas Méndez M, Piera Jaén G. Reliability of the Spanish version of a brief questionnaire on patient satisfaction with gastrointestinal endoscopy. Rev Esp Enferm Dig 2005; 97: 554-561.

Recibido: 10-01-05.

Aceptado: 16-03-05.

Correspondencia: Antonio Sánchez del Río. Clínica Hospiten Rambla. Rambla General Franco, 115. 38001 Santa Cruz de Tenerife. Tenerife. Fax: 9222910 88. e-mail: asanchez@hospiten.es

\section{INTRODUCTION}

Patient satisfaction has become one of the cornerstones of progressive quality improvement systems in hospitals. Satisfaction influences the choice of service provider made by patients or those close to them for future endoscopic exploration when a new health problem arises or in compliance with prescribed therapeutic measures (1). Today in gastrointestinal (GI) endoscopy practice, as in other areas of medicine, health care providers are striving to implement progressive improvement of quality programs $(2,3)$. Quality indicators of patient satisfaction may contribute to progressive improvement in patient collaboration and health care procedures. Thus, in a study on the use of flexible sigmoidoscopy for colon cancer screening, knowledge of the results of patient satisfaction surveys was shown to produce a progressive tendency for improvement (4).

A brief questionnaire adapted to GI procedures (GHAA-9m) is currently recommended by the ASGE (5). Despite some criticism, this is the only questionnaire used in published reports that allows comparisons between hospitals (6). A similar, though somewhat more complex, questionnaire using the same scale has been used to evaluate patient satisfaction with bronchoscopy (7).

Any questionnaire designed to measure patient satisfaction should fulfill a series of requisites. It should be simple to administer, whether by telephone, standard or electronic mail. The mGHAA-9 questionnaire uses a simple scale of five points, easy to understand and explain by a telephone interviewer. It is necessary to demonstrate that the questionnaire scale is valid for measuring satisfaction, i.e., the internal consistency of the questionnaire. In addition to reproducibility of the questionnaire under different circumstances, it should yield similar results, i.e., it should demonstrate external validity. The questionnaire validity should be constant regardless of the interviewer and other circumstances. 
The objective of this study was to determine the internal consistency and external validity of the mGHAA-9m questionnaire as adapted for GI endoscopy use and presented in Spanish. This adapted version is hereinafter referred to as the SmGHAA-9 questionnaire.

\section{PATIENTS AND METHODS}

\section{Patients}

A total of 485 outpatients (mean age $51 \pm 16$ years, $57 \%$ females) were prospectively interviewed for the study. Inclusion of the patients was consecutive and simultaneous in the endoscopic departments of two hospitals hereinafter called center $\mathrm{A}$ and center $\mathrm{B}$. The source of most patients $(n=443)$ was center $A$, a private hospital where patients either paid for the endoscopic procedure themselves or were financed by their health insurance companies, and were previously attended either by the center's physicians or external private practitioners.

The source of the remaining patients interviewed $(n=$ 72) was the endoscopic department of center B; these were patients on the waiting list of the public Canarian Health Service. The same procedure was followed in both centers: patients were systematically sedated with meperidine and midazolam for colonoscopy and midazolam for gastroscopy.

Thirty patients failed to respond, so they were excluded.

\section{Development and administration of the questionnaire}

The original questionnaire in English consists of seven questions pertaining to perceived patient experience (preappointment waiting period, waiting time on arrival at the center for the appointment, procedure briefing, physician courtesy, personnel courtesy, rating of physician's skill, overall rating of the procedure) and two questions on patient acceptance to undergo a further endoscopic intervention by the same physician and the same center. Our questionnaire was translated into Spanish by professional translators. The initial translation was tested with 20 patients who had undergone colonoscopy. We found that the question on the technical skills of the physician was left unanswered in 15 of these initial patients. Reasons included: amnesia secondary to the use of midazolam, failure to pay attention to the procedure, and lack of sufficient knowledge to judge physician's skill. In contrast to the standard procedure in the USA and other countries, it is not common practice to provide an additional monitor for patient viewing. For all these reasons we decided to substitute this question with another on perceived discomfort, rated using the same ordinal scale (Appendix I).
Our questionnaire was administered on the telephone by one of two different interviewers experienced in dealing with patients. All interviews were carried out approximately three weeks post-intervention.

\section{Statistical analysis}

\section{Internal consistency}

Ware and Davies have shown the utility of an ordinal scale of five levels for the evaluation of patient satisfaction (9). The internal consistency of this scale in the questionnaire for GI endoscopy was evaluated using Cronbach's alfa test, and the mean total inter-item correlation (mean CITC) using items 1-7 of the questionnaire (Appendix I). Internal consistency was tested for the whole sample of patients, for each of the interviewers, for each type of endoscopy (colonoscopy and EGD), and for each group of patients according to source. Cronbach's alfa values $>0.7$ and mean CITC $>0.4$ were considered adequate indicators of internal consistency (10).

\section{External validity}

The questionnaire, in a sealed stamped envelope, was delivered to 185 patients from center $\mathrm{A}$, who were then asked to complete it and return it a few weeks after the procedure. These patients were not told that they would be interviewed later by telephone. The correlation between individual items and total score for items 1-7 was studied (Appendix I). The total score of satisfaction could vary from 7 to 35 points; the higher the score, the greater the level of satisfaction. In order to evaluate the correlation between items 1-7, we used weighted kappa values, and for the correlation between total scores for both questionnaires we used Spearman's Rho test. Kappa performance was analyzed using standard nomenclature: $<0$ poor; 0 to 0.2 slight; 0.21 to 0.4 fair; 0.41 to 0.6 moderate; 0.61 to 0.8 substantial; 0.81 to 1 almost perfect. A Spearman's correlation coefficient $>0.7$ was considered adequate.

The study was approved by our local ethical committee.

\section{RESULTS}

\section{Internal consistency}

Table I shows Cronbach's alfa and mean CITC values for the whole sample of patients according to center, type of endoscopy, and interviewer. For both the whole sample and each subgroup (type of endoscopy, telephone interviewer, postal questionnaire, and hospital center) the values obtained for both tests were far higher than acceptable. 
Table I. Internal consistency of the questionnaire

\begin{tabular}{lcc}
\hline & Cronbach's alfa & Mean CTIC \\
\hline Global & 0.82 & 0.59 \\
Hospital A & 0.85 & 0.64 \\
Hospital B & 0.80 & 0.65 \\
Interviewer A & 0.79 & 0.52 \\
Interviewer B & 0.85 & 0.61 \\
Gastroscopy & 0.81 & 0.56 \\
Colonoscopy & 0.82 & 0.58 \\
\hline
\end{tabular}

Internal consistency of the questionnaire: global (all the questionnaires), in Centers $A$ and $B$, for each interviewer and type of gastrointestinal endoscopy. Estimated by Cronbach's alfa test and mean corrected total-item correlation.

\section{External validity}

Table II shows the weighted kappa values for each of the questionnaire items for the whole sample of patients, according to type of endoscopy and interviewer. These variables did not affect external validity. As can be seen from this table, all correlations were very good or excellent. Of note was the correlation for the question "overall rating of the visit", which may be used as a marker of satisfaction. The correlation between total score for both questionnaires was 0.78 , with a $\mathrm{p}$ value below 0.001 (Spearman's Rho).

Table II. External validity

\begin{tabular}{lccccc}
\hline Item & \multicolumn{5}{c}{ Weighted Kappa $\left(^{*}\right)$} \\
\hline Appointment & $A$ & $B$ & $G$ & $C$ & $T$ \\
Waiting-room time & 0.76 & 0.83 & 0.71 & 0.88 & 0.81 \\
Explanations & 0.69 & 0.74 & 0.72 & 0.73 & 0.73 \\
Physician courtesy & 0.72 & 0.77 & 0.67 & 0.79 & 0.74 \\
Personnel courtesy & 0.69 & 0.62 & 0.70 & 0.63 & 0.64 \\
Discomfort & 0.55 & 0.65 & 0.56 & 0.72 & 0.63 \\
Overall rating & 0.64 & 0.79 & 0.58 & 0.42 & 0.51 \\
\hline
\end{tabular}

Correlation between the questionnaire administered by telephone or mail, using weighted Kappa values, for different subgroups.

(*): Interviewers A, B, Gastroscopy, Colonoscopy and Total endoscopies.

\section{DISCUSSION}

Patient satisfaction with their health system and hospital centers has a great influence on future conduct when confronted with new health problems and compliance with medical indications. In gastrointestinal endoscopy, although different quality indicators aimed at progressive improvement are being introduced, markers of patient satisfaction allowing comparison between centers or benchmarking are relatively underdeveloped.
Different articles comparing aspects of endoscopy and patient satisfaction use non-comparable questionnaires and methods $(11,12)$.

Of the questionnaires specifically developed for gastrointestinal endoscopy, that of Salmon et al. using Likert's scale, and the one recommended by the American Society of Gastrointestinal Endoscopy (ASGE) stand out $(5,13)$. Questionnaires based on Likert-type scales are more complex (14). They require an elaboration of scales from patient affirmations. Each of these affirmations constitutes an item in the scale, which in turn is part of a question on satisfaction with a particular aspect. Translating this type of questionnaires into other languages is also labor-consuming. The administration of these questionnaires to populations that may considerably differ by means of a short telephone interview and standard or electronic mail may be impractical, and thus make general application or benchmarking difficult. Ware's ordinal 5-item scale facilitates the elaboration of simple-to-administer questionnaires (9). It has been extensively used in the Group Health Association of America-9 survey of 32 items, and a reduced and modified version was adopted by ASGE for use in gastrointestinal endoscopy (mGHAA-9) $(5,15,16)$. We selected this questionnaire as the basis for the Spanish version to measure satisfaction, and proceeded to validate it. Given that the scale is constant for the set of 7 key items, we used internal consistency statistical methods (Cronbach's alfa test and mean corrected item-total correlations) to study reliability of our questionnaire. In addition, we studied reproducibility of the test by means of a test-retest method using a postal and telephone interview with the same patients. All values obtained showed good overall reliability under different circumstances: type of endoscopy, interviewers, standard mail or telephone interviews (Tables I and II) (17). To our knowledge, there are no other similar studies involving gastrointestinal endoscopy and the validation of such a simple questionnaire. Although Ware's scale was maintained for the 7 key items, we decided to use a combined validation method including internal consistency and external validity, since the application of internal validation methods (like Cronbach's alfa or the mean corrected item-total correlations) for the study of different questions (waiting time, attention by personnel, etc.) may be questionable. However, by using both methods we were able to demonstrate a good reliability (Tables I and II).

This questionnaire may be an adequate means of comparison between centers for benchmarking. It is easy for the user to understand, administration is simple by telephone, and results are reliable. However, the suitability of certain items included has been questioned. Yacavone et al. interviewed a group of patients who had undergone GI endoscopy to evaluate the importance they attached to a series of aspects related to satisfaction (18). This group of patients considered highly important an aspect not in- 
cluded in the original questionnaire in English, namely discomfort during the procedure, and one not included by us, namely the endoscopist's technical skill. In our questionnaire we included "patient discomfort", but decided to eliminate the question on technical skill given our first 20 patients' inability to respond. Reasons were: amnesia originated by the systematic sedation of patients, absence of a monitor display for patient viewing, and especially, most of our patients stated that they lacked the necessary information and experience to judge physician's skills, mainly because this was their first endoscopy. We decided to use a relatively prolonged period between endoscopy and its rating since our main objective was to evaluate the patient's lingering impression of the procedure. This long-term impression we considered to be less influenced by the potential disease itself and/or the findings, so that decisions taken after the procedure should now be based on a final opinion that the user would convey to others.

One of the main characteristics of the mGHAA- 9 and SmGHAA-9 questionnaires is the use of an easily applied ordinal 5-point scale (Appendix I). This scale has been shown to be most adequate in the construction of simple questionnaires to evaluate patient satisfaction (14). New items may be incorporated when considered important for patient satisfaction. The main contribution by our study is the reliability of this scale for application in gastrointestinal endoscopy patient ratings, regardless of whether the questions/items included in the questionnaire are modifiable according to what patients or physicians consider important. Thus, in our opinion, the questionnaire is flexible and can be adjusted to the needs of individual endoscopic units, while maintaining the scale and global rating ( $7^{\text {th }}$ item, Appendix 1) as a measure of overall satisfaction.

The questionnaire may be a good indicator of the evolution of patient satisfaction in systems adopting progressive quality improvement in the course of their health-care function. On using the questionnaire it is necessary to consider that other factors, apart from those covered by the items themselves, may have a marked influence on patient satisfaction. In one study on patient satisfaction with bronchoscopy the patient's health status prior to the procedure had a great impact on patient satisfaction (12). Many other factors, such as information from family and friends, patient attitude towards medical information, and public image of the health center, may have a marked influence on responses to a questionnaire on satisfaction, and must be taken into account when interpreting results.

Ware's ordinal 5-point scale, as used in the mGHAA-9 questionnaire as modified for endoscopy, is also valid for the study of patient satisfaction with endoscopy when translated into Spanish. The questionnaire is valid, and validity is maintained under various circumstances. It may be reliably applied to the Spanish-speaking community.

\section{Appendix 1}

The Spanish modified GHAA-9 questionnaire with English translation

1. How long you waited to get an appointment:

Excellent Very good Good Fair Poor

2. Length of time spent waiting at the office for the procedure: Excellent Very good Good Fair Poor

3. The personal manner (courtesy, respect, sensitivity, friendliness) of the physician who performed your procedure:

Excellent Very good Good Fair Poor

4. The personal manner (courtesy, respect, sensitivity, friendliness) of the nurses and other support staff:

Excellent Very good Good Fair Poor

5. Adequacy of explanation of what was done for you, all your questions answered:

Excellent Very good Good Fair Poor

6. Discomfort that you felt during the endoscopic procedure:

Excellent Very good Good Fair Poor

7. Overall rating of the visit:

Excellent Very good Good Fair Poor

8. Would you have the procedure done again by this physician? Yes No

9. Would you consider having this procedure done again at this facility? Yes No

\section{REFERENCES}

1. Ware JE Jr, Davies AR. Behavioral consequences of consumer dissatisfaction with medical care. Eval Program Plann 1983; 6: 291-7.

2. Brown DR, Goldstein JL. Quality assurance in the endoscopy unit: an emphasis on outcomes. Gastrointest Endosc Clin N Am 1999; 9: 595608 .

3. Johanson JF. Continuous quality improvement in the ambulatory endoscopy center. Gastrointest Endosc Clin N Am 2002; 12: 351-66.

4. Larsen IK, Grotmol T, Bretthauer M, Gondal G, Huppertz-Hauss G, Hofstad B, et al. Continuous evaluation of patient satisfaction in endoscopy centres. Scand J Gastroenterol 2002; 37: 850-5.

5. Johanson JF, Schmitt CM, Deas TM, Eisen GM, Freeman M, Goldstein JL, et al. Quality and outcomes assessment in gastrointestinal endoscopy. Gastrointest Endosc 2000; 9: 827-30.

6. Harewood GC, Yacavone RF, Locke GR 3rd, Wiersema MJ. Prospective comparison on endoscopy patient satisfaction surveys: e-mail versus standard mail versus telephone. Am J Gastroenterol 2001; 96: 3312-7.

7. Lechtzin N, Rubin HR, White P, Jenckes M, Diette GB. Patient satisfaction with bronchoscopy. Am J Respir Crit Care Med 2002; 166 : 1326-31.

8. Weech-Maldonado R, Morales LS, Elliott M, Spritzer K, Marshall G, Hays RD. Race/ethnicity, language, and patients' assessments of care in Medicaid managed care. Health Serv Res 2003; 38: 789-808.

9. Ware JE, Hays RD. Methods for measuring patient satisfaction with specific medical encounters. Med Care 1988; 26: 393-402.

10. Han SW, Gregory W, Nylander D, Tanner A, Trewby P, Barton R, et al. The SIBDQ: further validation in ulceratives colitis patients. Am J Gastroenterol 2000; 95; 145-51. 
11. Jackson JL, Osgard E, Fincher RK. Resident participation in flexible sigmoidoscopy does not affect patient satisfaction. Am J Gastroenterol 2000; 95: 1563-6.

12. Stern MA, Fendrick AM, McDonnell WM, Gunaratnam N, Moseley R, Chey WD. A randomized, controlled trial to assess a novel colorectal cancer screening strategy: the conversion strategya comparison of sequential sigmoidoscopy and colonoscopy with immediate conversion from sigmoidoscopy to colonoscopy in patients with an abnormal screening sigmoidoscopy. Am J Gastroenterol 2000; 95: 2074-9.

13. Salmon P, Shah R, Berg S, Williams C. Evaluating customer satisfaction with colonoscopy. Endoscopy 1994; 26: 342-6.

14. Trochim MK, Lickert scaling. In: Trochim MK, ed. Research method knowledge base. Cornell University, 2002. Available at: http://trochim.human.cornell.edu/kb/scallik.htm

15. Wallace P, Haines A, Harrison R, Barber JA, Thompson S, Roberts J, et al. Design and performance of a multi-centre randomised controlled trial and economic evaluation of joint teleconsultations. BMC Family Practice 2002; 3: 172-9.

16. Rubin HR, Gandek B, Rogers WH, Kosinski M, McHorney CA, Ware JE Jr. Patient's ratings of outpatient visits in different practice settings. JAMA 1993; 270: 835-40.

17. Trochim MK, Types of reliability. In: Trochim MK, ed. Research method knowledge base. Cornell University, 2002. Available at:

http://trochim.human.cornell.edu/kb/reltypes.htm

18. Yacavone RF, Locke R 3rd, Gostout CJ, Rockwood TH, Thieling S, Zinsmeister AR, et al. Factors influencing patient satisfaction with GI endoscopy. Gastrointest Endosc 2001; 53: 703-10. 